\title{
A cara descubierta en favor de los animales: Francia, el 'Code Civil' y la Constitución
}

\author{
Keywords: Animales y Code civil francés; animales como cosas; animales como seres sensibles
}

La República Francesa ha emprendido, desde este otoño de 2013, un camino sin retorno, destinado a poner fin a la mala vida de los animales.

La iniciativa ha partido, entre otros, de un grupo, "Ecolo-Ethik", que encabeza la senadora Chantal Jouanno, quien ha desempeñado tareas de alta responsabilidad en el Gobierno de Francia desde hace años. Este nuevo "think-tank" ha recabado la colaboración de profesionales de reconocido prestigio, para trabajar por las mejora de la situación jurídica de los animales, en torno a varios niveles (político, jurídico, de enseñanza y de pensamiento) y un propósito. El propósito es la reforma de la Constitución y del Code civil en tema de animales. Se trata de reconocer jurídicamente a los animales como lo que son: seres sintientes, que merecen un estatuto jurídico distinto y mejor que el que tienen reconocido, a día de hoy, en el sistema jurídico francés, que no es otro que el de cosas en propiedad.

La Codificación francesa, ha sido, desde su publicación, la enseña y el modelo del Derecho continental. Al esfuerzo codificador francés, bajo el impulso de Napoleón, se debe la configuración jurídica de la Europa continental, de toda Latinoamérica, de Japón y de Turquía. Se trata, como es bien sabido, de un sistema de Derecho anclado en la tradición jurídica romana, que considera a los animales como fuerzas de trabajo, dentro de un modelo de sociedad eminentemente agrícola. Por ello, y en coherencia con el sistema romano de propiedad, los animales se encuadran dentro de los bienes que forman parte del patrimonio del hombre.

Como he tenido ocasión de referir en otras ocasiones, que los animales entraran en el sistema jurídico romano dentro de la categoría de cosas, fue, en sí mismo, un gran avance del pensamiento jurídico. Que dicha categorización se repitiera en el S.XIX en el Code Napoleon, no supuso ninguna alteración, pues la sociedad continuaba siendo eminentemente agrícola y, a pesar de que ya hubiera voces de pensadores que se cuestionaban el tratamiento de los animales como cosas, la inercia del sistema impidió que se repensara la calificación de los animales como algo distinto de las cosas en propiedad. Distinta es la situación actual y a ello responde, una vez más, la iniciativa de Francia, que esperamos que tenga el mismo efecto ejemplificador y dinamizante que tuvo, en su momento, el Code civil.

La diferencia hoy en día radica en dos aspectos de relieve. Uno es el cambio social respecto a los animales; el otro los conocimientos científicos que permiten afirmar que los animales son seres sensibles. Ambos vectores, antes separados, son hoy en día -gracias a la legislación europea sobre Bienestar Animal-, inseparables. En efecto, la sociedad contempla, de forma muy generalizada, a los animales como seres que hay que respetar y cuya vida y protección es tan importante, como lo es el cuidado del medio ambiente. Contribuye a este cambio social, un fenómeno, hoy generalizado, que es la incorporación de los animales al medio urbano, lo que hace que los Animales de Compañía formen parte de la vida cotidiana de millones de familias en todo el mundo, en todos los niveles de la sociedad. Junto a estos datos, la ciencia ha demostrado, de forma incuestionable, que los animales son seres sensibles al dolor, al sufrimiento y al estrés, pero también a la tranquilidad, al bienestar y a las emociones positivas. 
actuación respecto a los animales para todos los Estados Miembros. Queda pues, que los sistemas jurídicos propios de cada Estado de la Unión, se adecúen a estas nuevas exigencias y reformen sus sistemas jurídicos.

En esta perspectiva se entiende la reforma que ha iniciado Francia, sin ambages, con decisión y conocimientos, para cambiar la agenda política y que los animales pasen a primer plano. Se trata de hacer realidad esta iniciativa y que la columna vertebral del sistema jurídico francés, el Code civil y, la Constitución reconozcan a los animales como seres sintientes.

Estoy asistiendo, como miembro de la Comisión de expertos nombrada por el Senado, a la "Mesa redonda sobre el estatuto jurídico del animal", que tuvo lugar en París el 5 de noviembre. El próximo 16 de diciembre asisto, en calidad de Directora del Máster en Derecho Animal y Sociedad de la UAB, a la "Mesa redonda sobre Derecho Animal y enseñanza". En Octubre tuvo lugar una "Mesa redonda sobre Animales y Políticas", de la que se informa en la edición de la web de este mes y, en Enero, tendrá lugar la última "Mesa redonda sobre Animales y corrientes de pensamiento".

Estamos asistiendo a un avance importante en favor de la reforma del estatuto jurídico de los animales. No se puede ignorar lo que otros países han hecho en los años 90, como Alemania, Austria o Suiza, pero actualmente parece decisiva la iniciativa francesa, por lo que tiene de reflexión a cara descubierta en favor de los animales. Otros países, como el nuestro, no tardaremos en seguir este ejemplo.

LA EDITORA

Teresa Giménez-Candela Catedrática de Derecho Romano Animal Law Profesor Universitat Autònoma de Barcelona 